\title{
A Combinatorial Buffered Oxide Etching Method for High-Power Cladding Light Stripper
}

\author{
Elif Yapar Yıldırım ${ }^{1}$, Ali Karatutlu ${ }^{1}$, Ekin Teslime Balk ${ }^{1}$, Yakup Midilli ${ }^{1}$ and Bülend Ortaç ${ }^{1}$ \\ 1. UNAM-National Nanotechnology Research Center and Institute of Material Science and Nanotechnology, 06800, Bilkent University, \\ Ankara, Turkey
}

High-power fiber lasers have been applied in many areas due to their advantages such as high beam quality, compact structure, flexibility and high efficiency. However, the absorption of the pump light is limited and a residual pumped light keeps propagating in the cladding. This residual pumped light affects the beam quality and can damage the whole system. Therefore, an efficient removal of excess high-power cladding light is critical for the safe operation of the high-power fiber lasers and high beam quality [1]. Adding a new structure to the cladding of the fiber leading to interrupt total internal reflection in the clad and scatter away the unwanted pump light is the generalized approach for a cladding light stripper (CLS) device fabrication. Also, it is important to scatter all the unwanted light uniformly along the CLS. Etching the fiber for surface damage and recoating the fiber [2] are two general methods for stripping the cladding light [3-5].

In this paper, an improved CLS fabrication method is presented using stain etching and vapor-phase etching in which the buffered oxide etchant (BOE 7:1) was utilized in a house-made PTFE bath. In particular, we focused on clarifying the effects of the different morphological structures obtained using the chemical etching methods separately and combined. The combined method led us obtaining a better performance of a CLS device with an optimum surface morphology. Figure 1.A. shows both the crystal-like structures in the order of 40-50 $\mu \mathrm{m}$ and nano-sized hillocks as a result of the stain etching and the vapor-phase etching methods respectively. The AFM studies in Figure 1.B reveal that height of the crystal-like structures approaches to the $\mu \mathrm{m}$-scale. And, an all-glass device that provides a cladding stripping loss of $\sim 17.2 \mathrm{~dB}$ (Figure 1.C.) in a $\sim 390 \mu \mathrm{m}$ diameter and $12 \mathrm{~cm}$ length. When the output from a $333 \mathrm{~W}$ of two diodes was launched into the cladding of the fiber at the input to the cladding stripper, then $6.2 \mathrm{~W}$ of remaining radiation was measured at the output.
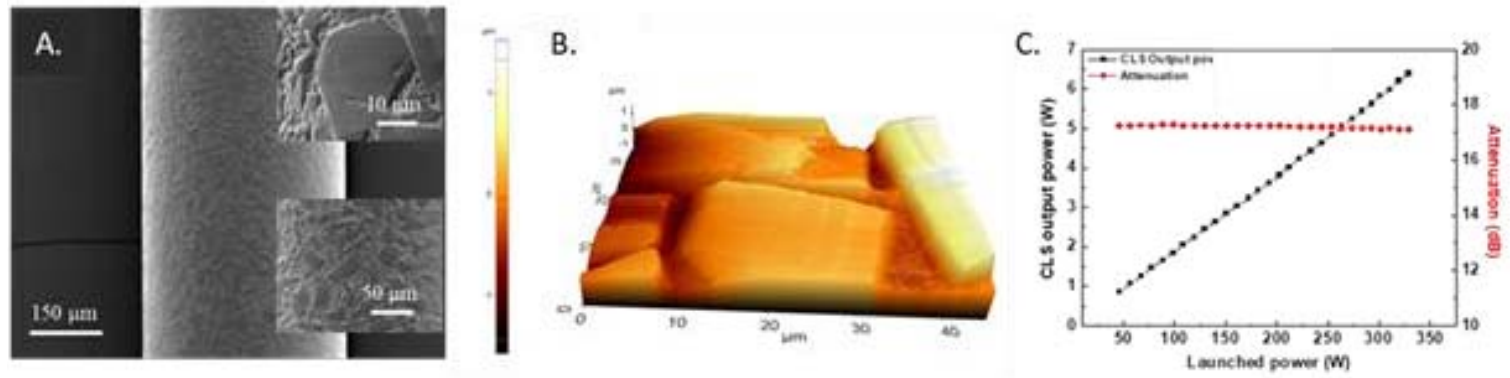

Fig. 1 A. The SEM image, B. the AFM image and C. the high-performance stripping of the device fabricated using combined method.

In conclusion, a combined method using the stain etching and vapor-phase etching routes was developed first time with the operation of BOE for the formation of a cladding light stripper device with both high-performance and robustness.

\section{References}

[1] A. Kliner, K.-C. Hou, M. Plötner, C. Hupel, T. Stelzner, T. Schreiber, R. Eberhardt, and A. Tünnermann, "Fabrication and evaluation of a 500 W cladding-light stripper," in Advanced Solid-State Lasers Congress (OSA, 2013), 8616, p. AM2A.3

[2] P. Yan, J. Sun, Y. Huang, D. Li, X. Wang, Q. Xiao, and M. Gong, "Kilowatt-level cladding light stripper for high-power fiber laser," Appl. Opt. 56(7), 1935 (2017).

[3] W. Guo, Z. Chen, H. Zhou, J. Li, and J. Hou, "Cascaded Cladding Light Extracting Strippers for High Power Fiber Lasers and Amplifiers," IEEE Photonics J. 6(3), 1-6 (2014)

[4] K. Boyd, N. Simakov, A. Hemming, J. Daniel, R. Swain, E. Mies, S. Rees, W. Andrew Clarkson, and J. Haub, "CO_2 laser-fabricated cladding light strippers for high-power fiber lasers and amplifiers," Appl. Opt. 55(11), 2915 (2016).

[5] A. Babazadeh, R. R. Nasirabad, A. Norouzey, K. Hejaz, R. Poozesh, A. Heidariazar, A. H. Golshan, A. Roohforouz, S. N. T. Jafari, and M. Lafouti, "Robust cladding light stripper for high-power fiber lasers using soft metals," Appl. Opt. 53(12), 2611 (2014). 